\title{
Effect of Ce and Mn co-doping on photocatalytic performance of sol-gel $\mathrm{TiO}_{2}$
}

\author{
Imen Tbessi ${ }^{\mathrm{a}}$, Mónica Benito ${ }^{\mathrm{b}}$, Elies Molins ${ }^{\mathrm{b}}$, Jordi LIorca ${ }^{\mathrm{c}}$, Azza Touati ${ }^{\mathrm{a}}$, Sami Sayadi ${ }^{\mathrm{d}}$, \\ Wahiba Najjar ${ }^{\mathrm{a}, \mathrm{e}}$
}

${ }^{a}$ Laboratory of Materials Chemistry and Catalysis, Faculty of Science of Tunis, University of Tunis-El Manar, 2092 - El Manar Tunis, Tunisia.

${ }^{b}$ Institut de Ciència de Materials de Barcelona (ICMAB-CSIC), c/ Til·lers, 1, Campus UAB, 08193 Bellaterra, Spain.

'Institute of Energy Technologies, Department of Chemical Engineering and Barcelona Research Center in Multiscale Science and Engineering, Universitat Politècnica de Catalunya, EEBE, 08019 Barcelona, Spain.

${ }^{\mathrm{d}}$ Laboratory of Environmental Bioprocesses, Center of Biotechnology of Sfax, B.P. 1177, 3018 Sfax, Tunisia.

${ }^{\mathrm{e}}$ Higher Institute of Preparatory Studies in Biology and Geology of Soukra, University of Carthage, 1054 - Amilcar Tunis, Tunisia.

\begin{abstract}
Co-doped titanium dioxide was synthesized by doping with manganese (Mn) and cerium (Ce) through a sol-gel method for the degradation of diclofenac (DCF). The synthesized products were successfully characterized by X-ray diffraction (XRD), Raman spectroscopy, Transmission electron microscopy (TEM), Scanning electron microscopy (SEM), Nitrogen physisorption at $77 \mathrm{~K}, \mathrm{X}$-ray photoelectron spectroscopy (XPS), UV-Vis diffuse reflectance (UV-DRS), photoluminescence spectroscopy (PL) and total organic carbon (TOC). It was shown that co-doping increased the specific surface area, improved the visible light absorption and extended the lifetime of photogenerated charge carriers. Furthermore, the results of the photocatalytic experiments show that the photodegradation rate of diclofenac can be approached by pseudo first-order kinetics and it followed the Langmuir-Hinshelwood model very well. The co-doped catalyst with $0.6 \% \mathrm{Mn}$ and $1 \% \mathrm{Ce}$ molar ratios appeared to be the most photoactive catalyst with $94 \%$ of DCF removal and an apparent rate constant of $0.012 \mathrm{~min}^{-1}$.
\end{abstract}

Keywords: Photocatalysis; titanium dioxide; co-doping; manganese and cerium; diclofenac. 


\section{Introduction}

Concern about the water pollution is growing due to the presence of emerging contaminants in water, which disrupts the aquatic ecosystem and threatens our health. In the last years, the increasing of pharmaceuticals compounds in wastewater is considered as an emerging environmental problem due to their toxic effects to the survival of aquatic animals and plants or even human health and persistence into the aquatic medium [1-4]. Among these compounds, diclofenac is a non-steroidal anti-inflammatory drug (NSAID) used to reduce inflammation and to treat the painful disease of rheumatic and non-rheumatic origin. It is one of the most frequently detected pharmaceuticals in many municipal sewage treatment plants (STP), effluents and in the receiving aquatic bodies since its biodegradation and natural attenuation are limited due to its antibacterial nature and chemical stability under normal environmental conditions [5-7]. Generally, NSAIDs such as diclofenac (DCF) have the capacity to bio-accumulate in the tissues of organisms, thus affecting the endocrine functions of aquatic biota like mussels and fishes [8]. The investigations concerning diclofenac impact on aquatic species indicated that DCF can be accumulated in liver kidney, gills and muscle tissues of rainbow trouts and causes cytological alterations after 28 days of exposure even at concentration of $1 \mu \mathrm{L}^{-1}$ [9]. In an exposure study to diclofenac, Lee et al. found that DCF adversely affected the growth in egg phase of fish Japanese medaka and resulted in significant reduction of hatchability and delay in hatching [10]. Due to these harmful effects, in 2015 diclofenac was included in the European Union (EU) first watch list for emerging water pollutants [11]. Thus, there is a considerable need to treat diclofenac contaminated wastewater effluents and detoxification before discharging them to various bodies [12].

The conventional wastewater treatment methods are not designed to completely remove the recalcitrant contaminants. Consequently, a more promising technology-based on Advanced Oxidation Processes (AOPs) has been studied for handling and achieving a complete decontamination of such effluents [13]. These processes are based on the formation of reactive species, which have a high oxidizing power to degrade a wide variety of pollutants [14-15]. Among the various AOPs, heterogeneous photocatalysis is one of the most effectively processes used in the degradation of organic pollutants containing in wastewater. Thereby, various catalysts have been applied in the removal of persistent pollutants from water [4, 16-18]. Among them, titanium dioxide was broadly used in heterogeneous photocatalysis as a suitable semiconductor owing to its various merits such as, high oxidizing power, photostability and nontoxicity nature [19]. The photodecomposition and 
mineralization of DCF in water by $\mathrm{UV}-\mathrm{A} / \mathrm{TiO}_{2}$ were reported by Achilleos et al. to elucidate the effect of various parameters [20]. Martinez et al. have studied the catalytic degradation of diclofenac using $\mathrm{TiO}_{2}$ nanostructured materials under near UV and UV light irradiation and investigated the factors affecting the kinetics of the photolysis such as, type and load of catalyst, the addition of $\mathrm{H}_{2} \mathrm{O}_{2}$ and the presence of dissolved $\mathrm{O}_{2}$. They also proposed a detailed DCF mechanism [21]. In other studies, Hua et al. studied the degradation of diclofenac by $\mathrm{TiO}_{2}$ nanotube arrays electrode by surface sensitization with copper nanoparticles. In addition to that, they described a possible photoelectrocatalytic pathway [22]. Unfortunately, the efficiency of $\mathrm{TiO}_{2}$ catalyst is hindered by its wide band gap energy $(3.2 \mathrm{eV})$ and the fast recombination rate of the free generated charge. In this respect, many researchers are working on the promotion of the efficacy of titanium oxide in photocatalysis. One of the promising ways is the modification of $\mathrm{TiO}_{2}$ by doping with various elements [23-24]. In particularly, transition metals and rare earth metals ions have been attempted as potential dopants to enhance the performance of titania [25-26]. Among these metals, manganese has been explored by many researchers due to its ability to introduce defect levels into the forbidden gap of $\mathrm{TiO}_{2}$, which leads to extend the visible light absorption. Deng et al. attributed the high visible light photocatalytic activity of the $\mathrm{Mn}$-doped $\mathrm{TiO}_{2}$ nanopowders to the narrow band gap, smaller average grain sizes and the increase of the lifetime of charge carriers [27]. Kamble et al. founded that $\mathrm{Mn}^{2+}$ doped $\mathrm{TiO}_{2}$ nanoparticles increase the degradation of malachite green dye upon UV and visible light irradiation [28]. Cerium has also been proved to be an effective dopant for improving the response of $\mathrm{TiO}_{2}$ by efficient band gap narrowing and hindering the electron-hole recombination, which increase the quantum yield in photocatalytic process. In addition, cerium doping can improve the surface adsorption of the catalyst and increases the number of oxygen vacancies [29]. Nguyen et al. reported that the enhanced visible light absorption resulting from the specific $4 \mathrm{f}$ electronic configuration of cerium plays a vital role in the production of electron-hole pairs to promote the visible light response of $\mathrm{TiO}_{2}$ [29]. Touati et al. prepared Ce doped $\mathrm{TiO}_{2}$ catalysts with different molar percentage through a sol-gel method and demonstrated that the highest photodegradation of textile wastewater was achieved with $1 \% \mathrm{Ce}$, which mainly due to the weaker band gap energy and an efficient charge separation [26].

It has been shown by earlier studies that the introduction of different dopants or the co-doping of $\mathrm{TiO}_{2}$ is always better compared to single doped catalyst due to the positive synergistic effect between the dopants. For instance, Myilsamy et al. showed that indium and cerium co- 
doped mesoporous $\mathrm{TiO}_{2}$ nanocomposites exhibited excellent activity in the decomposition of methylene blue and the results were confirmed by total organic carbon analysis [30]. It has been reported that titania co-doped with La and V showed higher photocatalytic activity on the degradation of Reactive Blue 52 than mono-doped $\mathrm{TiO}_{2}$ [31]. Thota et al. demonstrated that the photodecomposition of Orange-II under visible light was greatly enhanced by the coexistence of manganese and phosphorus on the $\mathrm{TiO}_{2}$ matrix [32].

Inspired by the positive effects of the manganese and cerium in photocatalytic degradation of organic pollutants, we selected $\mathrm{Mn} / \mathrm{Ce}$ as co-dopants to improve their cumulative effect on the removal of diclofenac. In the present study, we report the effect of manganese and cerium codoping on the degradation of diclofenac from aqueous suspensions by the $\mathrm{TiO}_{2}$ photocatalysis process. The catalysts were prepared by the sol-gel method, since it offers considerable advantages in terms of excellent control of textural and structural properties, high purity and homogeneity of the materials [33-35]. Subsequently, the obtained nanomaterials were characterized by conventional characterization techniques, including X-ray diffraction, Raman spectroscopy, Transmission electron microscopy, Scanning electron microscopy, Nitrogen physisorption at $77 \mathrm{~K}, \mathrm{UV}-\mathrm{Vis}$ diffuse reflectance, photoluminescence spectroscopy, X-ray photoelectron spectroscopy and total organic carbon. Finally, the performance of these catalysts and their photodegradation kinetics were discussed.

\section{Experimental}

\subsection{Materials}

Titanium (IV) isopropoxide [(Ti( $\left.\left(\mathrm{OCH}\left(\mathrm{CH}_{3}\right)_{2) 4}\right)\right]$, cerium (III) nitrate hexahydrate (Ce $\left.\left(\mathrm{NO}_{3}\right)_{3} \cdot 6 \mathrm{H}_{2} \mathrm{O}\right)$ and manganese (II) nitrate hexahydrate $\left(\mathrm{Mn}\left(\mathrm{NO}_{3}\right)_{2} \cdot 6 \mathrm{H}_{2} \mathrm{O}\right)$ were used as precursors for $\mathrm{Ti}, \mathrm{Ce}, \mathrm{Mn}$, respectively and bought at Aldrich. Ethyl acetoacetate $\left(\mathrm{C}_{6} \mathrm{H}_{10} \mathrm{O}_{3}\right.$, from Fluka), absolute ethanol $\left(\mathrm{C}_{2} \mathrm{H}_{5} \mathrm{OH}\right.$, from Merck) and nitric acid $\left(\mathrm{HNO}_{3}\right.$, from Sharlab) were added during the preparation of the photocatalysts. Diclofenac sodium salt (DCF) (98 $\%$ ) was supplied from Sigma-Aldrich and ultrapure water was also employed throughout the all experiments.

\subsection{Synthesis of photocatalysts}

For doped $\mathrm{TiO}_{2}$ preparation; manganese (II) nitrate hexahydrate $(0.6 \% \mathrm{Mn}$ molar ratio $\mathrm{Mn} / \mathrm{TiO}_{2}$ ) or cerium (III) nitrate hexahydrate $\left(1 \%\right.$ molar ratio $\left.\mathrm{Ce} / \mathrm{TiO}_{2}\right)$ were first dissolved in $12.5 \mathrm{~mL}$ of absolute ethanol, followed by the addition of $1.6 \mathrm{~mL}$ of ethyl acetoacetate as a 
complexing agent, and then $3.8 \mathrm{~mL}$ of titanium (IV) isopropoxide was added into the solution. The whole mixture was kept under stirring at room temperature for $30 \mathrm{~min}$. Then $1.25 \mathrm{~mL}$ of nitric acid $\left(0.1 \mathrm{~mol} \mathrm{~L}^{-1}\right)$ was added drop wise into the above mixture for hydrolysis and condensation reaction, the stirring was continued until a yellow gel was obtained. Thus, the resulting gel was dried in an autoclave under supercritical ethanol conditions $\left(\mathrm{T}=243{ }^{\circ} \mathrm{C}, \mathrm{P}=\right.$ 63 bar). The aerogel was crushed to get a fine powder and further calcined in $\mathrm{O}_{2}$ at $500{ }^{\circ} \mathrm{C}$ for 3 hours to obtain the catalyst. The co-doped materials were prepared following the same procedure as monodoped materials but with a molar ratio of $\mathrm{Mn} / \mathrm{TiO}_{2}$ at $0.6 \%$ of manganese and 1 or $2 \% \mathrm{Ce}$ molar ratios of $\mathrm{Ce} / \mathrm{TiO}_{2}$.

\subsection{Physical characterization}

The crystalline phases of the prepared samples were identified by powder X-ray diffraction (PXRD, XPERT-PRO) with $\mathrm{Cu} \mathrm{K}$ s source $(\lambda=1.54 \AA$ ) and the High Score Plus Software. The average crystallite size (D) was calculated using the Scherrer equation:

$$
\mathrm{D}=\mathrm{k} \lambda / \beta \cos \theta
$$

Where $\mathrm{D}$ is the average crystallite size, $\mathrm{k}$ is Scherrer constant $(0.89), \lambda$ is the wavelength of the $\mathrm{X}$-ray radiation $\left(\mathrm{Cu} \mathrm{K}_{\alpha}=1.54 \AA\right), \beta$ is the full width at half maximum of the diffraction peaks and $\theta$ is the diffraction angle. Raman spectra were recorded with a LabRam HR instrument (Horiba Jobin-Yvon) in the range of $100-1000 \mathrm{~cm}^{-1}$ at $20{ }^{\circ} \mathrm{C}$ with spectral resolution of $4 \mathrm{~cm}^{-1}$. A $514 \mathrm{~nm}$ Ar-Kr 2018-RM laser and a CCD detector cooled at $-75{ }^{\circ} \mathrm{C}$ were used. The average power at the surface of catalysts was set at $1 \mathrm{~mW}$. Transmission Electron Microscope (TEM) images were obtained using a JEOL 1210 TEM operating at 120 kV. Scanning Electron Microscope (SEM) and Energy-dispersive X-ray spectroscopy (EDS) methods were performed with a QUANTA FEI 200 FEG-ESEM. Nitrogen adsorptiondesorption isotherms at $77 \mathrm{~K}$ were recorded on a Micromeritics ASAP 2020 nitrogen adsorption apparatus. Prior to analysis, the samples were degassed at $200{ }^{\circ} \mathrm{C}$ for $4 \mathrm{~h}$. The specific surface area was determined using the Brunauer-Emmett-Teller (BET) method and the pore-size distribution was investigated by the Barret-Joyner-Halenda (BJH) method. UVVisible diffuse absorption spectra were measured with Perkin Elmer Lambda 54 spectrometer equipped with an integrating sphere (RSA-PE 20) for band gap energy measurements. $\mathrm{BaSO}_{4}$ was used as a reference standard. Photoluminescence (PL) spectra of the catalysts were obtained on a Perkin-Elmer-Lambda S55 (LS55) spectrophotometer using a xenon lamp as the excitation source with a wavelength of $320 \mathrm{~nm}$. X-ray photoelectron spectroscopy (XPS) 
analyses were recorded using a SPECS system equipped with an Al anode XR50 source operating at $250 \mathrm{~W}$ and a Phoibos $150 \mathrm{MCD}-9$ detector. The pass energy of the hemispherical analyzer was set at $20 \mathrm{eV}$ and the energy step was set at $0.1 \mathrm{eV}$. All the binding energy (BE) values were referenced to the $\mathrm{C} 1 \mathrm{~s}$ peak located at $284.8 \mathrm{eV}$ as a reference standard. Ce and Mn leaching after a typical experiment were measured with 5100 ICP-OES from Agilent Technologies. In order to investigate the extent of mineralization, total organic carbon (TOC) measurements were done using a Shimadzu TOC-VCPH analyzer. The TOC conversion was calculated with the following equation before and after photodegradation:

$$
\text { TOC conversion }(\%)=\left(\operatorname{TOC}_{(0)}-\operatorname{TOC}_{(t)}\right) / \operatorname{TOC}_{(0)} \times 100
$$

Where TOC $_{(0)}$ and TOC $(t)$ are the initial TOC of DCF solution and after a specific reaction time $(\mathrm{t})$ of irradiation, respectively.

\subsection{Photocatalytic reaction experiments}

The photocatalytic activity of the catalysts was evaluated by studying the decomposition of diclofenac in aqueous solutions. In a typical procedure, the initial concentration of diclofenac was fixed at $10 \mathrm{mg} \mathrm{L}^{-1}$ and $50 \mathrm{mg} \mathrm{L}^{-1}$ of catalyst was added to the suspension. The experiments were performed at natural $\mathrm{pH}(\mathrm{ca} .6)$ in a circular glass reactor with a water circulation arrangement to maintain the constant temperature of the reaction medium. A $30 \mathrm{~W}$ ultraviolet lamp (VL-215LC) with a wavelength of $254 \mathrm{~nm}$ was employed as UV light source. Prior to irradiation, the suspension was magnetically stirred in darkness for 1 hour to attain adsorption-desorption equilibrium of DCF molecules on the catalyst surface. Aliquots of the suspension $(5 \mathrm{~mL})$ were withdrawn at time intervals of $30 \mathrm{~min}$ and were analyzed after filtration (pore size: $0.45 \mu \mathrm{m}$ ) to remove the catalyst particles. The concentration of diclofenac solution was ascertained by a spectrophotometer (SHIMADZU UV-vis-1800 apparatus) at a wavelength of $276 \mathrm{~nm}$, the maximum diclofenac absorbance in the visible region. The percentage of the photodegradation was calculated with the following equation:

$$
\text { Removal of diclofenac }(\%)=\left(A b s(0)-A b s_{(t)}\right) / A b s(0) \times 100
$$

Where $\operatorname{Abs}_{(0)}$ is the initial absorbance of DCF solution and Abs (t) is the absorbance after irradiation at various time intervals.

\section{Results and discussion}




\subsection{Physicochemical characterization of photocatalysts}

\section{Crystal structure}

The effect of co-doping on the crystal phase of $\mathrm{TiO}_{2}$ was investigated by PXRD. The PXRD patterns of the as-products are displayed in Fig (1). All the patterns revealed characteristic diffraction peaks at $2 \theta=25.3,37.9,48.1,54.0,55.2,62.7$ and $68.9^{\circ}$ assigned to the (101), (004), (200), (105), (211), (204) and (116) crystal faces of tetragonal anatase $\mathrm{TiO}_{2}$ form (JCPDS No. 21-1272). The diffraction peaks are sharp and intense, proving a good crystallinity of the materials. No peaks attributed to the presence of other metal phases are detected. This is understandable as these catalysts contain very small amounts of dopants (0.6 $\% \mathrm{Mn}$ and/or $1 \%$ or $2 \% \mathrm{Ce}$ ). The intensity of the diffraction peaks slightly decreased when compared to undoped titania. Previous works show that the lattice distortion and the formation of the defects can lead to a loss of the crystallinity [36-37]. On the other hand, a slightly variation in the lattice parameters was observed, probably due to the creation of surface oxygen vacancies to maintain charge neutrality condition [38-39].

Based on XRD data the crystallite sizes were calculated from the diffraction plane of anatase [101] using the Debye-Scherrer equation. The results regrouped in the Table (1) showed that the size decreased through the addition of dopants. Reflecting that doping with $\mathrm{Mn}$ and $\mathrm{Ce}$ species induced an inhibition effect on the crystallite growth of $\mathrm{TiO}_{2}$, which can be caused by the formation of Mn-O-Ti and Ce-O-Ti bounds on the catalyst surface [30, 40-41].

\section{Raman spectra}

Raman analysis was carried out to validate the previous crystal structural results. The Raman spectra of undoped $\mathrm{TiO}_{2}$ and $1 \% \mathrm{Ce}-0.6 \% \mathrm{Mn} / \mathrm{TiO}_{2}$ are reported in Fig (2). The dominated peaks located at $145,198,398,516$ and $640 \mathrm{~cm}^{-1}$ are relative to the specific vibrational modes $E_{1 \mathrm{~g}}, E_{2 \mathrm{~g}}, \mathrm{~B}_{1 \mathrm{~g}}, \mathrm{~A}_{1 \mathrm{~g}}+\mathrm{B}_{1 \mathrm{~g}}$ and $\mathrm{E}_{\mathrm{g}}$, respectively [42]. These findings are certainly indicating only the presence of pure anatase $\mathrm{TiO}_{2}$ phase [43] which are in complete agreement with the XRD results.

\section{TEM and SEM analyses}

TEM and SEM images of $1 \% \mathrm{Ce}-0.6 \% \mathrm{Mn} / \mathrm{TiO}_{2}$ catalyst are shown in Fig (3). As it can be seen it is morphologically well-dispersed and highly homogeneous. The most of the particles are of spherical shape and the average particle size is found to be about of $10 \pm 1 \mathrm{~nm}$. The 
EDS pattern confirms the presence of $\mathrm{Ti}, \mathrm{Mn}, \mathrm{Ce}$ and $\mathrm{O}$ elements on the co-doped sample. Furthermore, the SEM-EDX elemental mapping analysis (Fig (4)) reveals the homogeneous distribution of titanium (Ti), cerium (Ce), manganese $(\mathrm{Mn})$ and oxygen $(\mathrm{O})$ on the nanocomposite surface.

\section{Textural features}

The textural properties of the synthesized catalysts were obtained from nitrogen physisorption analyses at $77 \mathrm{~K}$. Fig (5) shows the $\mathrm{N}_{2}$ adsorption-desorption isotherms and pore size distribution curves of the samples. It can be observed that all the isotherms belong to type IV according to IUPAC classification with a type $\mathrm{H} 2$ hysteresis loop, characteristics of mesoporous solid whose surface is uniform and structured [44]. In addition, the pore size distributions obtained from the desorption branch indicate that the samples were homogeneous. The physical properties listed in Table (1) show that these products elaborated via sol-gel method demonstrate an important specific surface area ( $\left.\mathrm{S}_{\mathrm{BET}}\right)$ which varied in the range of $135-171 \mathrm{~m}^{2} \mathrm{~g}^{-1}$. Moreover, it seems that manganese and cerium co-doping increases the $\mathrm{S}_{\mathrm{BET}}$ having a synergistic effect. Among all the catalysts, the $1 \% \mathrm{Ce}-0.6 \% \mathrm{Mn} / \mathrm{TiO}_{2}$ catalyst exhibits the largest BET surface area $\left(171 \mathrm{~m}^{2} \mathrm{~g}^{-1}\right)$ and a high pore volume $\left(0.49 \mathrm{~cm}^{3} \mathrm{~g}^{-1}\right)$, thus improving the ability for organic pollutant adsorption [45]. However, at high cerium content ( $2 \%$ ), the surface area tends to slightly decrease, probably due to the blocking of the pores by the loading of cerium ions.

\section{Optical features}

The optical properties of the photocatalysts were evaluated by UV-Vis diffuse reflectance spectroscopy to assess the effect of co-doping on light absorption. The UV-Visible diffuse absorption spectra of the products are depicted in Fig (6).

Pure mesoporous $\mathrm{TiO}_{2}$ represents an absorption edge in the ultraviolet region, corresponding to the charge transfer between $\mathrm{O}^{2-}$ and $\mathrm{Ti}^{4+}[46]$. It is worth noting that co-doping caused a notable red shift in the absorption edge towards the visible region with the increase in cerium amount, due to the synergistic effect of the two dopants on the electronic structure of $\mathrm{TiO}_{2}$ [47]. This shift is also accompanied by a narrowing of the band gap energy of $\mathrm{TiO}_{2}$ network. Previous studies have described that this reduction of the band gap is attributed to the creation of new impurity energy levels in the band gap of the semiconductor [30, 36]. 
In the case of $0.6 \% \mathrm{Mn} / \mathrm{TiO}_{2}$ catalyst, the red shift is purely related to manganese doping. The charge-transfer transition between the d electrons of $\mathrm{Mn}^{2+}$ and the conduction/valence band of $\mathrm{TiO}_{2}$ results in the absorption edge in the visible region. In the case of $1 \% \mathrm{Ce} / \mathrm{TiO}_{2}$ and codoped samples, the mutual interaction between $\mathrm{Ti}^{4+}$ and $\mathrm{Ce}^{3+}$ with the specific $4 \mathrm{f}$ electronic configuration further contributes to increase significantly the absorption in the visible region $[40,48]$. It was found that both doped and co-doped $\mathrm{TiO}_{2}$ catalysts show a reduction of the band gap energy when compared to pure one (Table (1)). The $1 \% \mathrm{Ce}-0.6 \% \mathrm{Mn} / \mathrm{TiO}_{2}$ and $2 \% \mathrm{Ce}-0.6 \% \mathrm{Mn} / \mathrm{TiO}_{2}$ catalysts exhibit band gap energies equal to $2.43 \mathrm{eV}$ and $2.38 \mathrm{eV}$, respectively.

\section{Photoluminescence analysis}

The charge recombination process of the semiconductors was stated by photoluminescence emission spectra. The PL spectra of the as prepared catalysts are represented in Fig (7). Tripathi et al. reported that the PL spectrum of anatase $\mathrm{TiO}_{2}$ is ascribed to three types of physical origins: surface states, self-trapped excitons and oxygen vacancies [43].

It is found that the spectra of all samples showed emission peaks at $420 \mathrm{~nm}$ and $452 \mathrm{~nm}$, probably attributed to luminescence from the localized surface state due to the recombination of excited electrons-holes [49-50]. The band at $482 \mathrm{~nm}$ corresponds to the self-trapped excitons on $\mathrm{TiO}_{6}$ octahedral [51] while the emission peaks at the longer wavelength can be assigned to the color centers associated to oxygen vacancies [52].

The rate of charge recombination is directly proportional to the PL emission spectra of the catalysts. For our samples it was also observed that the PL spectra showed a change in the emission intensity of their spectra. The maximum intensity was obtained for undoped $\mathrm{TiO}_{2}$, indicating the higher recombination of electron and hole pairs. After doping and co-doping, the whole intensity of the PL spectra decreased significantly following this order: $\mathrm{TiO}_{2}>$ $1 \% \mathrm{Ce} / \mathrm{TiO}_{2}>0.6 \% \mathrm{Mn} / \mathrm{TiO}_{2}>2 \% \mathrm{Ce}-0.6 \% \mathrm{Mn} / \mathrm{TiO}_{2}>1 \% \mathrm{Ce}-0.6 \% \mathrm{Mn} / \mathrm{TiO}_{2}$. The co-doped sample $1 \% \mathrm{Ce}-0.6 \% \mathrm{Mn} / \mathrm{TiO}_{2}$ presents the lowest PL intensity, suggesting that it owns the highest effective charge separation among the prepared materials [53]. However, as $\mathrm{Ce}$ concentration increases, the PL intensity again increases. This would indicate that higher cerium concentration would allow the formation of recombination centers or new trap sites on the surface of the catalyst [50]. In fact, the excited electrons can be trapped by dopant ions and transferred to the catalyst surface, thus inhibiting the recombination process and favoring 
the production of a high number of hydroxyl radicals during the photocatalytic process, which hence improves the photocatalytic yield [26].

\section{XPS characteristics}

In order to study the chemical states of the different species on the surface of $\mathrm{TiO}_{2}$, XPS analyses were recorded. The representative XPS survey spectra of pure $\mathrm{TiO}_{2}$ and $1 \% \mathrm{Ce}$ $0.6 \% \mathrm{Mn} / \mathrm{TiO}_{2}$ indicate the presence of $\mathrm{Ti}, \mathrm{O}, \mathrm{C}, \mathrm{Ce}$ and $\mathrm{Mn}$ elements (Fig (S1) and Fig (S2)). The presence of carbon might be attributed to the adventitious carbon based contaminant. The Ti 2p XPS spectra show two peaks located at $458.9 \mathrm{eV}$ and $464.6 \mathrm{eV}$, correspond to Ti $2 \mathrm{p}_{3 / 2}$ and $\mathrm{Ti} 2 \mathrm{p}_{1 / 2}$, which indicate that $\mathrm{Ti}$ excites in the form of $\mathrm{Ti}^{4+}$ [54]. For $\mathrm{O} 1 \mathrm{~s}$ spectra, the peak at about $530 \mathrm{eV}$ is related to the lattice oxygen in $\mathrm{TiO}_{2}$. According to the literature, the broad Mn $2 p$ spectrum shows two spin-orbit doublet peaks for Mn 2 $\mathrm{p}_{3 / 2}$ and Mn 2 $\mathrm{p}_{1 / 2}$ located at BE of $641 \mathrm{eV}$ and $652 \mathrm{eV}$ respectively, indicating presumably the existence of $\mathrm{Mn}^{4+}$ and $\mathrm{Mn}^{3+}$ oxidation states [27-54]. The XPS spectrum of Ce $3 d$ can be assigned to $3 d_{5 / 2}$ and $3 d_{3 / 2}$ spinorbit states denoted as $\mathrm{U}$ and $\mathrm{V}$, respectively. The peaks $\mathrm{U}, \mathrm{U}$ ', U', , V, V', and V', can be attributed to the chemical state of $\mathrm{Ce}^{4+}$, while $\mathrm{U}^{\prime}$ and $\mathrm{V}^{\prime}$ correspond to $\mathrm{Ce}^{3+}$ state [55]. Thus, the cerium species present in both form of $\mathrm{Ce}^{4+}$ and $\mathrm{Ce}^{3+}$ on the surface of $\mathrm{TiO}_{2}$. The atomic ratio $\mathrm{Mn} / \mathrm{Ce}$ of the $1 \% \mathrm{Ce}-0.6 \% \mathrm{Mn} / \mathrm{TiO}_{2}$ sample estimated from XPS analyses was 0.42 .

\subsection{Photocatalytic removal of diclofenac}

\section{Preliminary studies}

\section{Effect of adsorption}

Diclofenac adsorption on catalyst surface was studied in darkness previous to initiate the photocatalytic experiments (Fig (8)). The results show that the adsorption removal of diclofenac reaches its maximum after $60 \mathrm{~min}$ and then it is quite constant, due to the saturation of the active sites of $\mathrm{TiO}_{2}$ with the organic pollutant. Thus, to achieve the adsorption equilibrium the suspension was magnetically stirred for $1 \mathrm{~h}$ in the dark before to irradiate with UV light. It was noticed that the adsorption in the dark was quantitatively insignificant in the presence of $\mathrm{TiO}_{2}$ without irradiation. This finding indicates that the drug was adsorbed on the catalyst surface instead of undergoing degradation.

\section{Effect of direct photolysis (UV) and photocatalysis (UV/TiO 2$)$}


As shown in Fig (8), the effect of the photolysis and the photocatalysis on the degradation of $10 \mathrm{mg} \mathrm{L}^{-1}$ initial DCF concentration. The experimental data for the photolysis demonstrate that diclofenac can be photodegraded when it is exposed to UV light in the absence of $\mathrm{TiO}_{2}$ catalyst, showing that the presence of UV light source may also produce free radicals in the reaction medium able to degrade the target compound. Nevertheless, the percentage of the degradation does not exceed $14 \%$ upon UV irradiation. The addition of mesoporous $\mathrm{TiO}_{2}$ nanoparticles ameliorates the photodegradation rate of DCF achieving about of $35 \%$ of DCF degradation after $120 \mathrm{~min}$ and $51 \%$ after $240 \mathrm{~min}$. In other study, Alalm et al. reported a 68 $\%$ removal of $50 \mathrm{mg} \mathrm{L}^{-1}$ initial DCF concentration after $180 \mathrm{~min}$ of solar irradiation using 0.4 $\mathrm{g} \mathrm{L}^{-1}$ of $\mathrm{TiO}_{2}$ [56]. Therefore, we can conclude that the DCF removal requires the introduction of a photocatalyst in the reaction medium.

Actually, the absorption of a photon by $\mathrm{TiO}_{2}$ permits the excitation of an electron to the empty conduction band and generates a positive hole in the valence band, according to Eq. (1):

Catalyst $+\mathrm{hv}(\lambda=254 \mathrm{~nm}) \longrightarrow \mathrm{h}^{+}{ }_{(\mathrm{VB})}+\mathrm{e}^{-}{ }_{(\mathrm{CB})}$

The electron can be trapped by molecular oxygen adsorbed on the surface of $\mathrm{TiO}_{2}$ for producing superoxide radical anions (Eq. (2)). These generated superoxide anions can then react with adsorbed water and $\mathrm{H}^{+}$to form a hydroperoxyl radicals $\left(\mathrm{HOO}^{\bullet}\right)$ and hydroxyl ions $\left(\mathrm{OH}^{-}\right)($Eq. (3)) and (Eq. (4)) [32]:

$$
\begin{aligned}
& \mathrm{O}_{2}+\mathrm{e}^{-}{ }_{(\mathrm{CB})} \longrightarrow \mathrm{O}_{2}^{-} \\
& \mathrm{O}_{2}^{-}+\mathrm{H}_{2} \mathrm{O} \longrightarrow \mathrm{HOO}^{\cdot}+\mathrm{OH}^{-} \\
& \mathrm{O}_{2}{ }^{-}+\mathrm{H}^{+} \longrightarrow \mathrm{HOO}^{\cdot}
\end{aligned}
$$

\section{Photodegradation kinetics of DCF molecule}

To assess the photocatalytic activities of the different products, experiments were conducted at $10 \mathrm{mg} \mathrm{L}^{-1}$ initial diclofenac concentration under $\mathrm{UV}_{(254 \mathrm{~nm})}$ irradiation at ambient temperature, $50 \mathrm{mg} \mathrm{L}^{-1}$ catalyst loading and inherent solution $\mathrm{pH}(\approx 6)$ in a reactor system.

The photodegradation rate of diclofenac can be expressed by a modified LangmuirHinshelwood (L-H) kinetic model [21]: 
$D=-\frac{d C}{d t}=\mathrm{k} \theta_{\mathrm{DCF}}=\mathrm{k} \frac{\mathrm{C} \mathrm{KDCF}}{1+\mathrm{C} \mathrm{KDCF}}$

Where, $\mathrm{D}$ is the rate of degradation $\left(\mathrm{mg} \mathrm{L}^{-1} \min ^{-1}\right), \mathrm{C}$ is DCF concentration $\left(\mathrm{mg} \mathrm{L}^{-1}\right), \mathrm{k}$ is the reaction rate constant $\left(\mathrm{mg} \mathrm{L}^{-1} \mathrm{~min}^{-1}\right), \mathrm{K}_{\mathrm{DCF}}$ is the adsorption equilibrium constant $\left(\mathrm{L} \mathrm{mg}^{-1}\right)$ and $\theta_{\text {DCF }}$ is the fraction of the site covered by diclofenac molecules. At low concentration of a pollutant in water $\left(1+\mathrm{C} \mathrm{K}_{\mathrm{DCF}} \leq 1\right)$, the $\mathrm{L}-\mathrm{H}$ equation (Eq. 5$)$ can be simplified to a first order kinetic model as follows:

$\mathrm{D}=\mathrm{k} \mathrm{K}_{\mathrm{DCF}} \mathrm{C}=\mathrm{K}_{\mathrm{app}} \mathrm{C}$

$\operatorname{Ln} \frac{\mathrm{C}(0)}{\mathrm{C}(\mathrm{t})}=\mathrm{K}_{\mathrm{app}} \mathrm{t}$

Where $\mathrm{K}_{\mathrm{app}}\left(\mathrm{min}^{-1}\right)$ represents the pseudo-first order rate constant, $\mathrm{C}_{(0)}$ and $\mathrm{C}_{(\mathrm{t})}$ are the concentrations of diclofenac at $\mathrm{t}=0$ and time $\mathrm{t}$, respectively. The apparent rate constants values were obtained from the slope of the plot $\operatorname{Ln}\left(\mathrm{C}_{(0)} / \mathrm{C}_{(\mathrm{t})}\right)$ versus time.

The kinetics results of DCF photo-oxidation are depicted in Table (2). By comparing the kinetics data, the highest rate constant $\left(0.012 \mathrm{~min}^{-1}\right)$ was observed for $1 \% \mathrm{Ce}-0.6 \% \mathrm{Mn} / \mathrm{TiO}_{2}$ and then decreased with the increase of cerium content $\left(2 \% \mathrm{Ce}-0.6 \% \mathrm{Mn} / \mathrm{TiO}_{2}\right)$ which may be due to the reduction of surface area. As illustrated in Fig (9) the as-synthesized catalysts are active and have demonstrated higher activities towards the photodecomposition of diclofenac within 240 min under UV light illumination than pure $\mathrm{TiO}_{2}$.

In comparison to pure and mono-doped titania, the co-doped nanocomposites with manganese and cerium ions have better catalytic efficiency for DCF decomposition due to the enhanced specific surface area, high adsorptivity of pollutant molecules, reduction of band gap energy and an effective charge separation. The highest catalytic performance was observed when the cerium and manganese contents were $1 \%$ and $0.6 \%$, respectively (sample: $1 \% \mathrm{Ce}$ $0.6 \% \mathrm{Mn} / \mathrm{TiO}_{2}$ ) and yielded about $94 \%$ of degradation with an apparent rate constant of 0.012 $\min ^{-1}$. Besides, the obtained results for the total organic carbon analysis (Table (2)) were in good agreement with the results of the diclofenac photodegradation and the $1 \% \mathrm{Ce}$ $0.6 \% \mathrm{Mn} / \mathrm{TiO}_{2}$ catalyst possesses also the highest percentage of TOC conversion (89\%) compared to the other materials.

\section{Proposed mechanism}


The proposed mechanism for the diclofenac degradation under UV irradiation in the presence of $\mathrm{Mn}-\mathrm{Ce} / \mathrm{TiO}_{2}$ catalyst is illustrated in Scheme (1). It is well known that the co-doping plays an important role for enhancing the catalytic activity of $\mathrm{TiO}_{2}$.

During the photocatalytic process, the excited $\mathrm{e}^{-} / \mathrm{h}^{+}$can be trapped by doped ions and then transferred to the adsorbed $\mathrm{O}_{2}$ and ${ }^{-} \mathrm{OH}$ molecules on the catalyst surface to form a large number of reactive species such as hydroxyl radicals and superoxide radicals, through the following reactions:

$$
\begin{aligned}
& \mathrm{M}^{\mathrm{n}+}+\mathrm{e}_{(\mathrm{CB})}^{-} \longrightarrow \mathrm{M}^{+(\mathrm{n}-1)} \\
& \mathrm{M}^{+(\mathrm{n}-1)}+\mathrm{O}_{2(\mathrm{ads})} \longrightarrow \mathrm{M}^{\mathrm{n}+}+{ }^{\cdot} \mathrm{O}_{2}^{-} \\
& \mathrm{M}^{+(\mathrm{n}-1)}+\mathrm{h}_{(\mathrm{VB})}^{+} \longrightarrow \mathrm{M}^{\mathrm{n}+} \\
& \mathrm{M}^{\mathrm{n}+}+{ }^{-} \mathrm{OH}_{(\mathrm{ads})} \longrightarrow \mathrm{M}^{+(\mathrm{n}-1)}+\cdot \mathrm{OH} \\
& \mathrm{M}^{+(\mathrm{n}-1)}=\mathrm{Ce}^{3+}, \mathrm{Mn}^{3+} \\
& \mathrm{M}^{\mathrm{n}+}=\mathrm{Ce}^{4+}, \mathrm{Mn}^{4+}
\end{aligned}
$$

Likewise, the generated holes can oxidize the adsorbed water molecules and/or can be captured by hydroxyl ions $\left(\mathrm{OH}^{-}\right)$on the surface of the catalyst to produce also hydroxyl radicals as shown in reactions (Eq. (12)) and (Eq. (13)).

$$
\begin{aligned}
& \mathrm{H}_{2} \mathrm{O}_{(\mathrm{ads})}+\mathrm{h}^{+}{ }_{(\mathrm{VB})} \longrightarrow \mathrm{H}^{+}+\cdot \mathrm{OH} \\
& -\mathrm{OH}_{(\mathrm{ads})}+\mathrm{h}^{+}{ }_{(\mathrm{VB})} \longrightarrow \cdot \mathrm{OH}
\end{aligned}
$$

\section{Stability}

Catalyst stability is very important for their potential applications. The cyclic photocatalytic stability of $1 \% \mathrm{Ce}-0.6 \% \mathrm{Mn} / \mathrm{TiO}_{2}$ was evaluated by repeating the experiments four times under the same reaction conditions. As shown, in Fig (10), the performance of the recycled catalyst after four successive cycles still remains an excellent photocatalytic response for the DCF degradation. And no leaching was observed for Ce and only $0.08 \mathrm{mg} / \mathrm{L}$ for $\mathrm{Mn}$ after $4 \mathrm{~h}$ of reaction. Thus, we can conclude that the $1 \% \mathrm{Ce}-0.6 \% \mathrm{Mn} / \mathrm{TiO}_{2}$ catalyst was stable during the photocatalytic degradation of diclofenac. 


\section{Conclusions}

The findings of this work proved that co-doping with manganese and cerium enhanced the physicochemical and the photocatalytic features of $\mathrm{TiO}_{2}$. The structural results showed only anatase form of $\mathrm{TiO}_{2}$ for the as-prepared catalysts. The textural and optical characterizations revealed that the co-existence of manganese and cerium species reduced the gap energy and increased significantly the surface area when compared to mono-doped and bare $\mathrm{TiO}_{2}$. From PL analysis, the co-doping seemed to prolong the lifetime of electron/hole pairs for the codoped sample. Moreover, kinetics analyses demonstrated that the photodegradation rate followed a pseudo first order kinetics according to Langmuir-Hinshelwood. The highest apparent rate was $0.012 \mathrm{~min}^{-1}$ and the maximum diclofenac removal besides the highest percentage of mineralization were achieved when using the co-doped $\mathrm{TiO}_{2}$ with $0.6 \% \mathrm{Mn}$ and $1 \% \mathrm{Ce}$. The improved activity of $1 \% \mathrm{Ce}-0.6 \% \mathrm{Mn} / \mathrm{TiO}_{2}$ sample was mainly attributed to its large surface area, the reduced band gap energy and the effective recombination delay of photo-induced charge carriers.

\section{Acknowledgements}

We acknowledge the Tunisian Ministry of Higher Education and Scientific Research for financial support. MB and EM thanks to Ministerio de Economía, Industria y Competitividad (MINECO/FEDER), Spain (Grants ENE2015-63969 and SEV2015-0496). JL is Serra Hunter Fellow and is grateful to ICREA Academia program and MINECO/FEDER project (ENE 2015-63969).

\section{References}

[1] A. Nikolaou, S. Meric, D. Fatta, Occurrence patterns of pharmaceuticals in water and wastewater environments, Anal. Bioanal. Chem. 387 (2007) 1225-1234.

[2] J. Rivera-Utrilla, M. Sánchez-Polo, M.A. Ferro-García, G. Prados-Joya, R. Ocampo-Pérez, Pharmaceutical as emerging contaminants and their removal from water. A review, Chemosphere. 93 (2013) $1268-1287$.

[3] M. Cheng, G. Zeng, D. Huang, C. Lai, Y. Liu, C. Zhang, J. Wan, L. Hu, C. Zhou, W. Xiong, Efficient degradation of sulfamethazine in simulated and real wastewater at slightly basic $\mathrm{pH}$ values using Co-SAM/ $\mathrm{H}_{2} \mathrm{O}_{2}$ fenton-like system. Water. Res. 138 (2018) 7-18. 
[4] C. Zhang, C. Lai, G. Zeng, D. Huang, C. Yang, Y. Wang, Y. Zhou, M. Cheng, Efficacy of carbonaceous nanocomposites for sorbing ionizable antibiotic sulfamethazine from aqueous solution, Water. Res. 95 (2016) 103-112.

[5] R. Andreozzi, M. Raffaele, P. Nicklas, Pharmaceuticals in STP effluents and their solar photodegradation in aquatic environment, Chemosphere. 50 (2003) 1319-1330.

[6] L. Rizzo, S. Meric, D. Kassinos, M. Guida, F. Russo, V. Belgiorno, Degradation of diclofenac by $\mathrm{TiO}_{2}$ photocatalysis: UV absorbance kinetics and process evaluation through a set of toxicity bioassays, Water. Res. 43 (2009) 979-988.

[7] L. A. Pérez-Estrada, M. I. Maldonado, W. Gernjak, A. Agüera, A. R. Fernández-Alba, M. M. Ballesteros, S. Malato, Decomposition of diclofenac by solar driven photocatalysis at pilot plant scale, Catal. Today. 101 (2005) 219-226.

[8] L. H. Santos, A. N. Araujoa, A. Fachini, A. Pena, C. Delerue-Matos, M. C. Montenegro, Ecotoxicological aspects related to the presence of pharmaceuticals in the aquatic environment, J. Hazard. Mater. 175 (2010) 47-95.

[9] D. Vogna, R. Marotta, A. Napolitano, R. Andreozzi, M. d'Ischia, Advanced oxidation of the pharmaceutical drug diclofenac with $\mathrm{UV} / \mathrm{H}_{2} \mathrm{O}_{2}$ and ozone, Water. Res. 38 (2004) 414-422.

[10] J. Lee, K. Ji, Y. Lim Kho, P. Kim, K. Choi, Chronic exposure to diclofenac on two freshwater cladocerans and Japanese medaka, Ecotoxicol. Environ. Saf. 74 (2011) 1216-1225.

[11] https://ec.europa.eu/jrc/en/news/first-watch-list-emeging-water-pollutants.

[12] Y. Zhang, S.U. Geissen, C. Gal, Carbamazepine and diclofenac: Removal in wastewater treatment plants and occurrence in water bodies, Chemosphere. 73 (2008) 1151-1161.

[13] L. Ferrando-Climent, R. Gonzalez-Olmos, A. Anfruns, I. Aymerich, L. Corominas, D. Barceló, S. Rodriguez-Mozaz, Elimination study of the chemotherapy drug tamoxifen by different advanced oxidation processes: Transformation products and toxicity assessment, Chemosphere. 168 (2017) 284-292.

[14] B. M. Souza, B. S. Souza, T. M. Guimaraes, T. F. Ribeiro, A. C. Cerqueira, G. L. Sant'Anna Jr, M. Dezotti, Removal of recalcitrant organic matter content in wastewater by means of AOPs aiming industrial water reuse, Environ. Sci. Pollut. Res. 23 (2016) 2294722956. 
[15] O. Bechambi, M. Chalbi, W. Najjar, S. Sayadi, Photocatalytic activity of ZnO doped with Ag on the degradation of endocrine disrupting under UV irradiation and the investigation of its antibacterial activity, Appl. Surf. Sci. 347 (2015) 414-420.

[16] Y. Yang, C. Zhang, C. Lai, G. Zeng, D. Huang, M. Cheng, J. Wang, F. Chen, C. Zhou, W. Xiong, $\mathrm{BiOX}(\mathrm{X}=\mathrm{Cl}, \mathrm{Br}, \mathrm{I})$ photocatalytic nanomaterials: Applications for fuels and environmental management, Adv. Colloid. Interface. Sci. 254 (2018) 76-93.

[17] E.A. Serna-Galvis, J. Silva-Agredo, A.L. Giraldo, O.A. Florez, R.A. Torres-Palma, Comparison of route, mechanism and extent of treatment for the degradation of a $\beta$-Lactam antibiotic by $\mathrm{TiO}_{2}$ photocatalysis, sonochemistry, electrochemistry and the photo-fenton system, Chem. Eng. J. 284 (2016) 953-962.

[18] W. Xiong, G. Zeng, Z. Yang, Y. Zhou, C. Zhang, M. Cheng, Y. Liu, L. Hu, J. Wan, C. Zhou, R. Xu, X. Li, Adsorption of tetracycline antibiotics from aqueous solutions on nanocomposite multi-walled carbon nanotube functionalized MIL-53(Fe) as adsorbent, Sci. Total Environ. 627 (2018) 235-244.

[19] R. Klaysri, T. Tubchareon, P. Praserthdam, One-step synthesis of amine-functionalized $\mathrm{TiO}_{2}$ surface for photocatalytic decolorization under visible irradiation, J. Ind. Eng. Chem. 45 (2017) 229-236.

[20] A. Achilleos, E. Hapeshi, N. Xekoukoulotakis, D. Mantzavinos, D. Fatta-Kassinos, Factors affecting diclofenac decomposition in water by $\mathrm{UV}-\mathrm{A} / \mathrm{TiO}_{2}$ photocatalysis, Chem. Eng. J. 161 (2010) 53-59.

[21] C. Martinez, M. Canle, M. I. Fernández, J. A. Santaballa, J. Faria, Aqueous degradation of diclofenac by heterogeneous photocatalysis using nanostructured materials, Appl. Catal. B: Environ. 107 (2011) 110-118.

[22] Z. Hua, Z. Dai, X. Bai, Z. Ye, P. Wang, H. Gu, X. Huang, Copper nanoparticles sensitized $\mathrm{TiO}_{2}$ nanotube arrays electrode with enhanced photoelectrocatalytic activity for diclofenac degradation, Chem. Eng. J. 283 (2016) 514-523.

[23] B. Liu, X. Zhao, The synergetic effect of $\mathrm{V}$ and Fe-co-doping in $\mathrm{TiO}_{2}$ studied from the DFT + U first-principle calculation, Appl. Surf. Sci. 399 (2017) 654-662. 
[24] Y. Liu, J. Wu, H. Lu, J. Wang, Y. Qu, L. Jing, Enhanced photocatalytic activities of commercial $\mathrm{P} 25 \mathrm{TiO}_{2}$ by trapping holes and transferring electrons for $\mathrm{CO}_{2}$ conversion and 2,4 dichlorophenol degradation, Mat. Res. Bull. 92 (2017) 23-28.

[25] C. Li, F. Xue, E. Ding, X. He, Glutaraldehyde assisted synthesis of collagen derivative modified $\mathrm{Fe}^{3+} / \mathrm{TiO}_{2}$ nanocomposite and their enhanced photocatalytic activity, Appl. Surf. Sci. 356 (2015) 852-861.

[26] A. Touati, T. Hammedi, W. Najjar, Z. Ksibi, S. Sayadi, Photocatalytic degradation of textile wastewater in presence of hydrogen peroxide: Effect of cerium doping titania, J. Ind. Eng. Chem. 35 (2016) 36-44.

[27] Q. R. Deng, X. H. Xia, M. L. Guo, Y. Gao, G. Shao, Mn-doped $\mathrm{TiO}_{2}$ nanopowders with remarkable visible light photocatalytic activity, Mater. Lett. 65 (2011) 2051-2054.

[28] R. Kamble, S. Sabale, P. Chikode, V. Puri, S. Mahajan, Structural and photocatalytic studies of hydrothermally synthesized $\mathrm{Mn}^{2+}-\mathrm{TiO}_{2}$ nanoparticles under $\mathrm{UV}$ and visible light irradiation, Mater. Res. Express. 3 (2016) 115005-115016.

[29] D.T. Nguyen, S. S. Hong, Synthesis of metal ion-doped $\mathrm{TiO}_{2}$ nanoparticles using twophase method and their photocatalytic activity under visible light irradiation, J. Nanosci. Nanotechnol. 16 (2016) 1911-1915.

[30] M. Myilsamy, V. Murugesan, M. Mahalakshmi, Indium and cerium co-doped mesoporous $\mathrm{TiO}_{2}$ nanocomposites with enhanced visible light photocatalytic activity, Appl. Catal. A: Gen. 492 (2015) 212-222.

[31] J. Nesi, D. D. Manojlovi, I. Andelkovi, B. P. Dojcinovi, P. J. Vulic, J. Krsti, G. M. Roglic, Preparation, characterization and photocatalytic activity of lanthanum and vanadium co-doped mesoporous $\mathrm{TiO}_{2}$ for azo-dye degradation, J. Mol. Catal. A: Chem. 378 (2013) 6775 .

[32] S. Thota S, S. Tirukkovalluri, S. Bojja, Effective catalytic performance of manganese and phosphorus co-doped titania nanocatalyst for orange-II dye degradation under visible light irradiation, J. Environ. Chem. Eng. 2 (2014) 1506-1513.

[33] I. Lazar, J. Kalmar, A. Peter, A. Szilagyi, E. Gyori, T. Ditroi, I. Fabiana, Photocatalytic performance of highly amorphous titania-silica aerogels with mesopores: The adverse effect 
of the in situ adsorption of some organic substrates during photodegradation, Appl. Surf. Sci. 356 (2015) 521-531.

[34] R. Gherbi, Y. Bessekhouad, M. Trari, Optical and transport properties of Sn-doped $\mathrm{ZnMn}_{2} \mathrm{O}_{4}$ prepared by sol-gel method, J. Phys. Chem. Solids. 89 (2016) 69-77.

[35] H. Atout, M. G. Alvarez, D. Chebli, A. Bouguettoucha, D. Tichit, J. Llorca, F. Medina, Enhanced photocatalytic degradation of methylene blue: Preparation of $\mathrm{TiO}_{2} /$ reduced graphene oxide nanocomposites by direct sol-gel and hydrothermal methods, Mat. Res. Bull. 95 (2017) 578-587.

[36] K. Gu, B. Chem, X. Wang, J. Wang, J. Fang, J. Wu, X. Yang, Preparation, friction, and wear behaviors of cerium-doped anatase nanophases in rapeseed oil, Ind. Eng. Chem. Res. 53 (2014) 6249-6254.

[37] K. Anandan, V. Rajendran, Influence of dopant concentrations ( $\mathrm{Mn}=1,2$ and 3 mol \%) on the structural, magnetic and optical properties and photocatalytic activities of $\mathrm{SnO}_{2}$ nanoparticles synthesized via the simple precipitation process, Superlattices. Microstruct. 85 (2015) 185-197.

[38] L. Gomathi Devi, N. Kottam, S. Girish Kumar, Preparation and characterization of Mndoped titanates with a bicrystalline framework: Correlation of the crystallite size with the synergistic effect on the photocatalytic activity, J. Phys. Chem. C. 113 (2009) 15593-15601.

[39] B. Yacoubi, L. Samet, J. Bennaceur, A. Lamouchi, R. Chtourou, Properties of transition metal doped-titania electrodes: Impact on efficiency of amorphous and nanocrystalline dyesensitized solar cells, Mater. Sci. Semicon. Process. 30 (2015) 361-367.

[40] S. Paul, P. Chetri, A. Choudhury, Effect of manganese doping on the optical property and photocatalytic activity of nanocrystalline titania: Experimental and theoretical investigation, $\mathrm{J}$. Alloys. Compd. 583 (2014) 578-586.

[41] S. J. Dillon, M. P. Harmer, Intrinsic grain boundary mobility in alumina, J. Am. Ceram. Soc. 89 (2006) 3885-3887.

[42] S. Kment, H. Kmentova, Z. Hubicka, J. Olejnicek, M. Cada, J. Krysa, Enhanced photocatalytic activity of silver-doped nanoparticulate $\mathrm{TiO}_{2}$ thin films with respect to the method of doping, Res. Chem. Intermediat. 41 (2015) 9343-9355. 
[43] A. K. Tripathi, M. C. Mathpal, P. Kumar, M. K. Singh, M. A. G. Soler, A. Agarwal, Structural, optical and photoconductivity of $\mathrm{Sn}$ and $\mathrm{Mn}$ doped $\mathrm{TiO}_{2}$ nanoparticles, J. Alloys Compd. 622 (2015) 37-47.

[44] C. Pulgarin, J. Kiwi, V. Nadtochenko, Mechanism of photocatalytic bacterial inactivation on $\mathrm{TiO}_{2}$ films involving cell-wall damage and lysis, Appl. Catal. B: Environ. 128 (2012) 179183.

[45] Y-F. Li, D. Xu, J. Oh, W. Shen, X. Li, Y. Yu, Mechanistic Study of codoped titania with nonmetal and metal ions: A case of C + Mo codoped $\mathrm{TiO}_{2}$, ACS. Catal. 2 (2012) 391-398.

[46] F. B. Li, X. Z. Li, M. F. Hou, K. W. Cheah, W.C.H. Choy, Enhanced photocatalytic activity of $\mathrm{Ce}^{3+}-\mathrm{TiO}_{2}$ for 2-mercaptobenzothiazole degradation in aqueous suspension for odour control, Appl. Catal. A: Gen. 285 (2005) 181-189.

[47] K. Zhang, X. Wang, T. He, X. Guo, Y. Feng, Preparation and photocatalytic activity of B-N co-doped mesoporous $\mathrm{TiO}_{2}$, Powder. Technol. 253 (2014) 608-613.

[48] T. Tong, J. Zhang, B. Tian, F. Chen, D. He, M. Anpo, Preparation of Ce-TiO 2 catalysts by controlled hydrolysis of titanium alkoxide based on esterification reaction and study on its photocatalytic activity, J. Colloid. Interf. Sci. 315 (2007) 382-388.

[49] F. Knorr, C. Mercado, J. McHale, Trap-State distributions and carrier transport in pure and mixed-Phase $\mathrm{TiO}_{2}$ : Influence of contacting solvent and interphasial electron transfer, J. Phys. Chem. C. 112 (2008) 12786-12794.

[50] P. Sun, L. Liu, S-C. Cui, J-G. Liu, Synthesis, characterization of Ce-doped $\mathrm{TiO}_{2}$ nanotubes with high visible light photocatalytic activity, Catal. Lett. 144 (2014) 2107-2113.

[51] A. K. Tripathi, M. K. Singh, M. Mathpal, S. Mishra, A. Agarwal, Study of structural transformation in $\mathrm{TiO}_{2}$ nanoparticles and its optical properties, J. Alloys. Compd. 549 (2013) $114-120$

[52] M. Pelaez, N. Nolan, S. Pillai, M. Seery, P. Falaras, A. Kontos, P. M. Dunlop, J. J. Hamilton, J. Byrne, K. O'Shea, M. Entezari, D. Dionysiou, A review on the visible light active titanium dioxide photocatalysts for environmental applications, Appl. Catal. B: Environ. 125 (2012) 331-349. 
[53] Y. Yang, Z. Zeng, C. Zhang, D. Huang, G. Zeng, R. Xiao, C. Lai, C. Zhou, H. Guo, W. Xue, M. Cheng, W. Wang, J. Wang, Construction of iodine vacancy-rich BiOI/Ag@ AgI Zscheme heterojunction photocatalysts for visible-light-driven tetracycline degradation: transformation pathway and mechanism insight, Chem. Eng. J. 349 (2018) 808-821.

[54] T. Boningari, P. Ettireddy, A. Somogyvari, Y. Liu, A. Vorontsov, C. McDonald, P. Smirniotis, Influence of elevated surface texture hydrated titania on Ce-doped $\mathrm{Mn} / \mathrm{TiO}_{2}$ catalysts for the low-temperature SCR of $\mathrm{NO}_{\mathrm{x}}$ under oxygen-rich conditions, J. Catal. 325 (2015) 145-155.

[55] Y. Z. Wang, Y. S. Wu, H. Yang, M. Wang, X. G. Shi, C. Wang, S. W. Zhang, Effect of calcination temperature on the microstructure and antimicrobial activity of boron and cerium co-doped titania nanomaterials, Mater. Technol. 33 (2018) 48-56.

[56] M. Alalm, A. Tawfik, S. Ookawara, Enhancement of photocatalytic activity of $\mathrm{TiO}_{2}$ by immobilization on activated carbon for degradation of pharmaceuticals, J. Environ. Chem. Eng. 4 (2016) 1926-1937. 


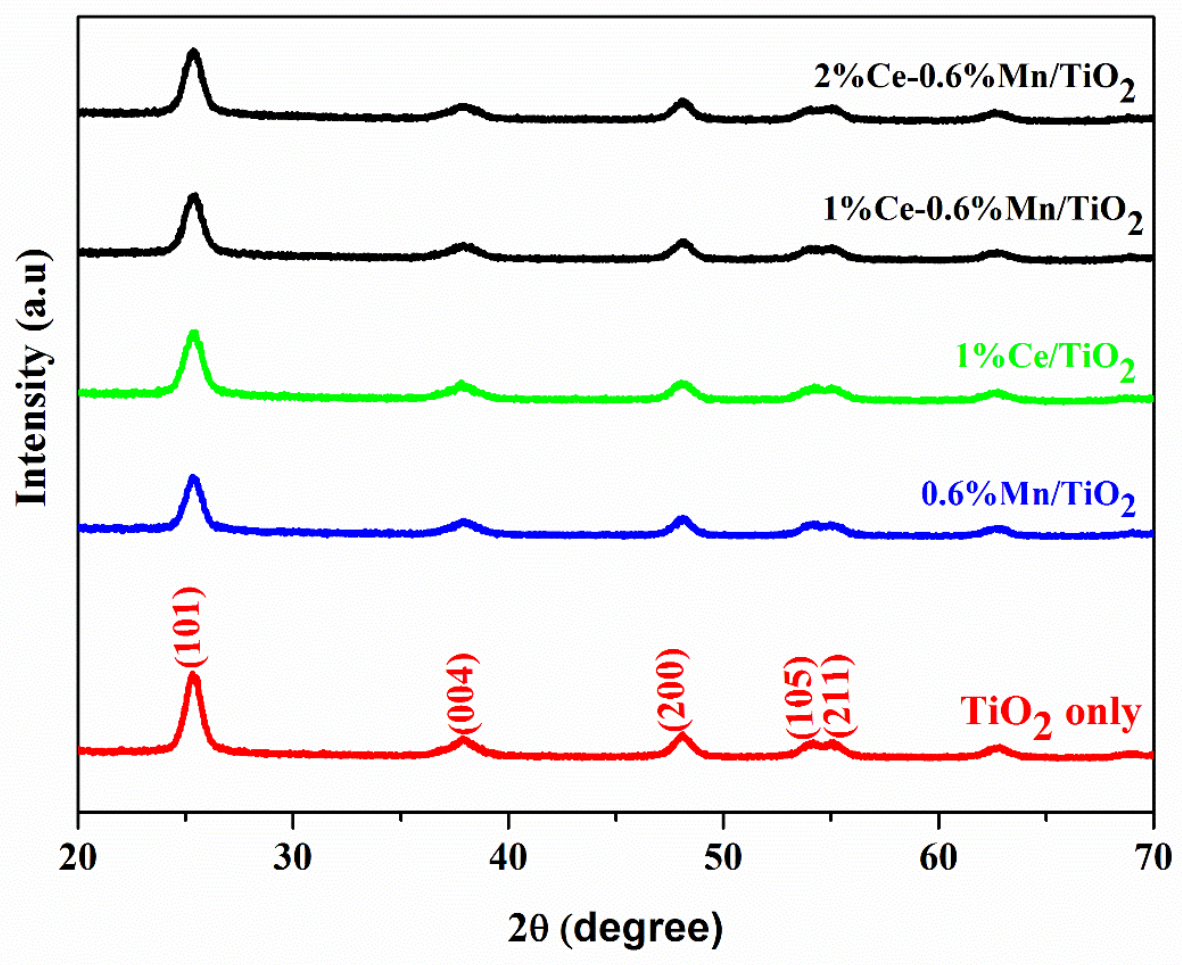

Fig (1): XRD patterns of the catalysts.

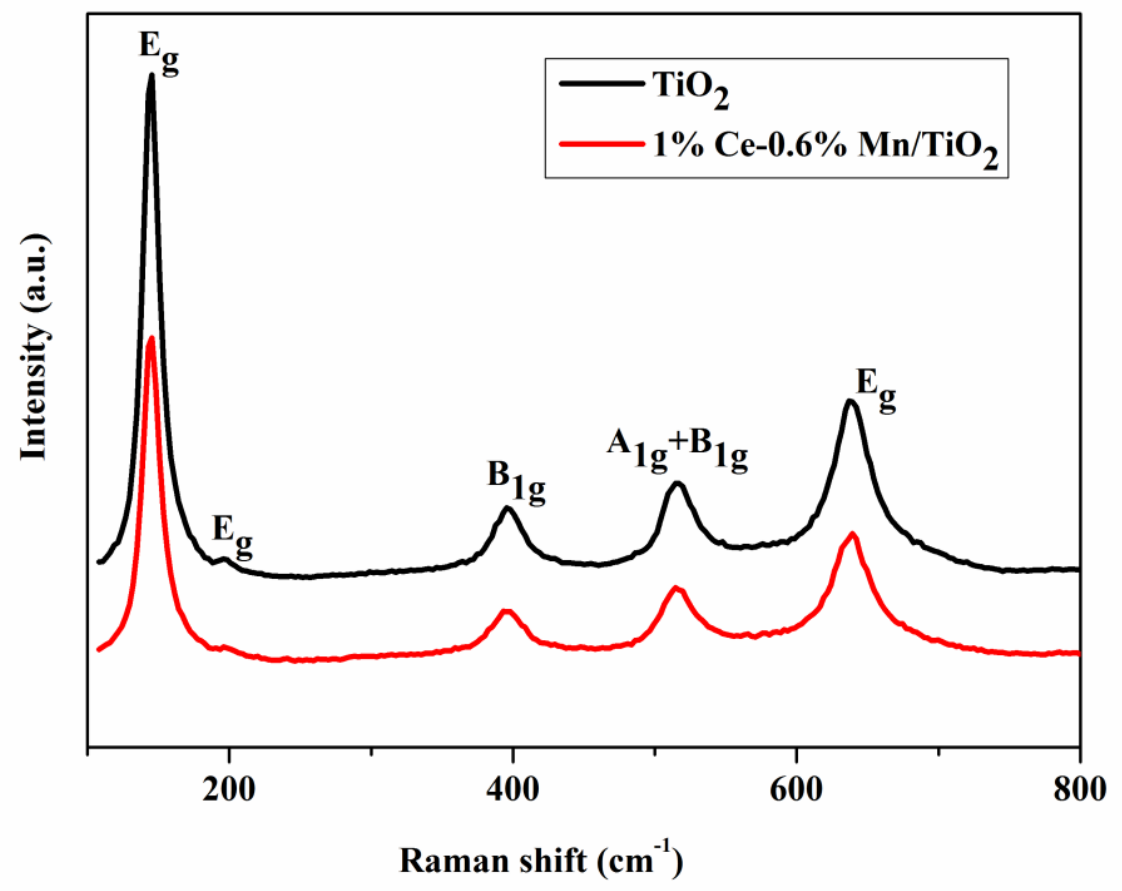

Fig (2): Raman spectra of the samples. 

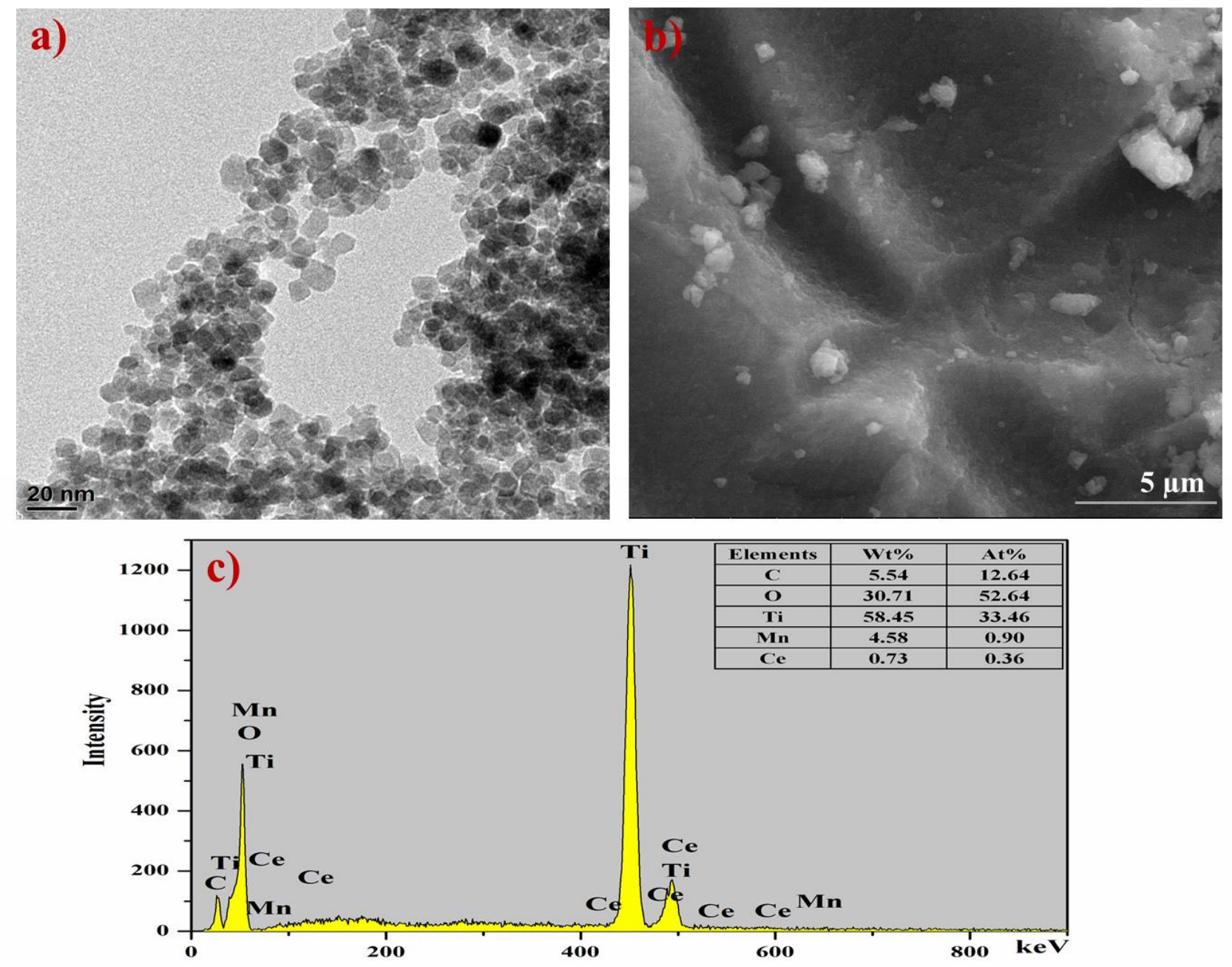

Fig (3): a) TEM image, b) SEM image and c) EDS spectrum of $1 \% \mathrm{Ce}-0.6 \% \mathrm{Mn} / \mathrm{TiO}_{2}$. 


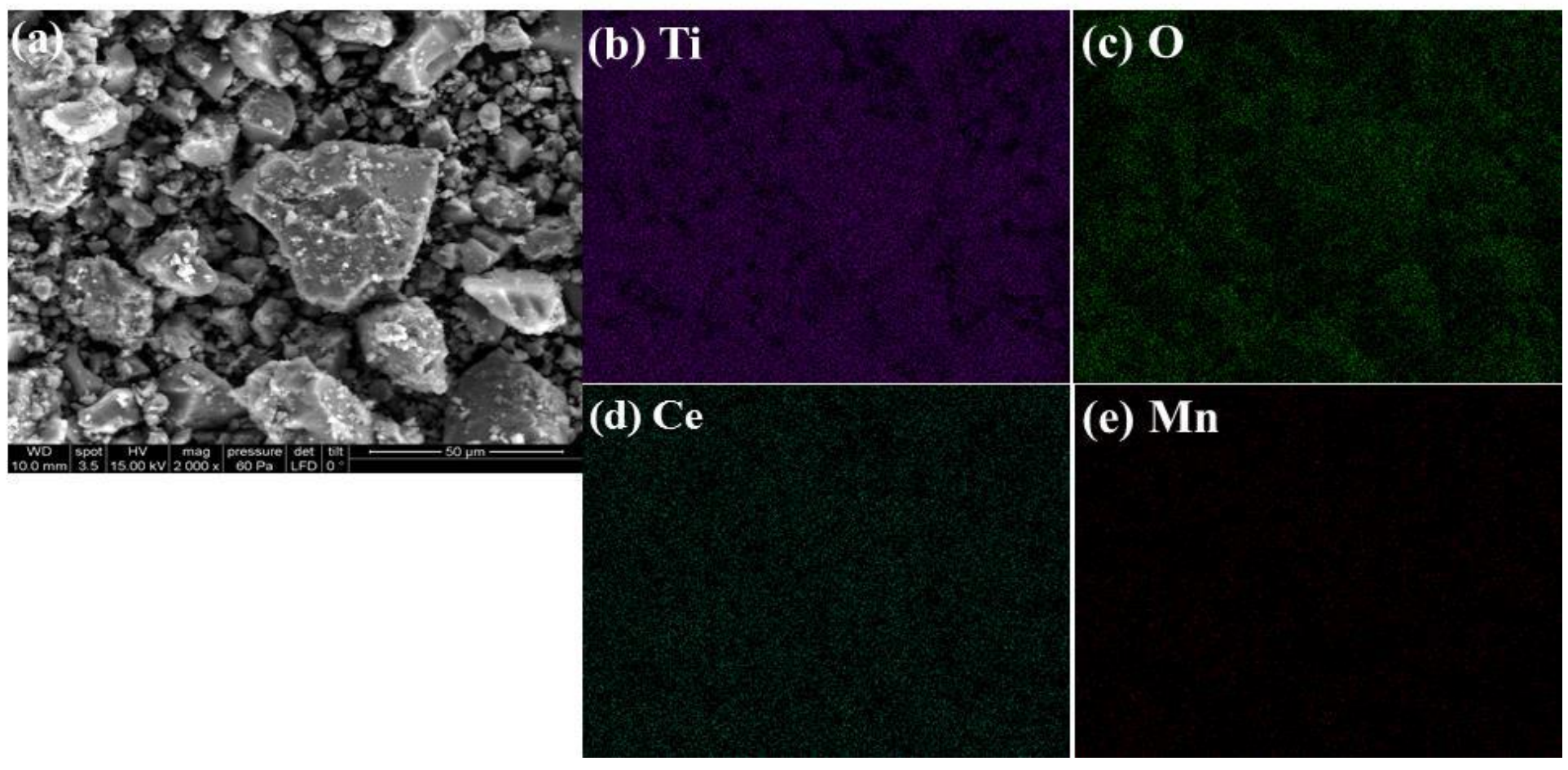

Fig (4): (a)SEM image and (b)-(e) EDX elemental mapping analysis of $1 \% \mathrm{Ce}-0.6 \% \mathrm{Mn} / \mathrm{TiO}_{2}$. 
(a)
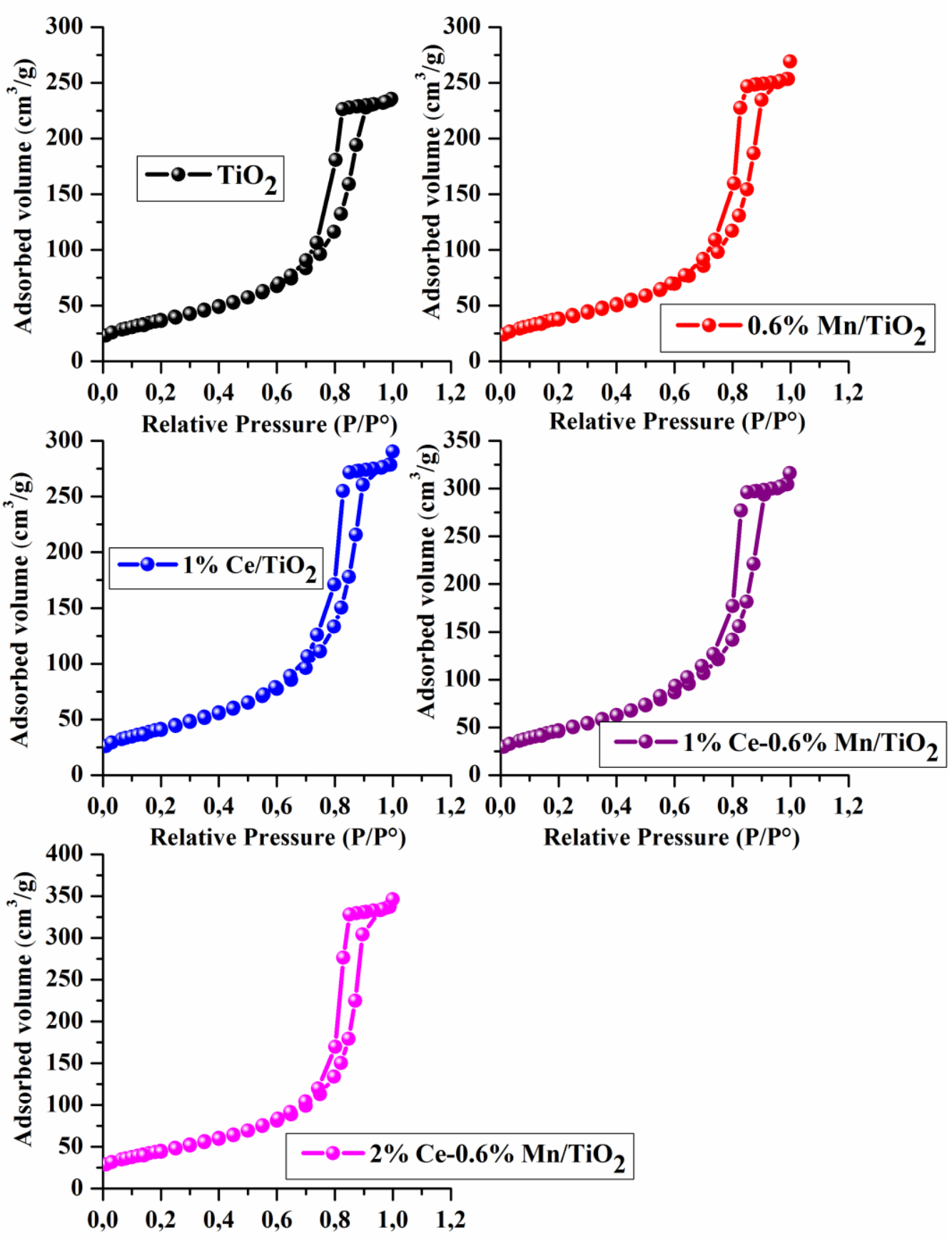

Relative Pressure $\left(\mathrm{P} / \mathrm{P}^{\circ}\right)$ 
(b)
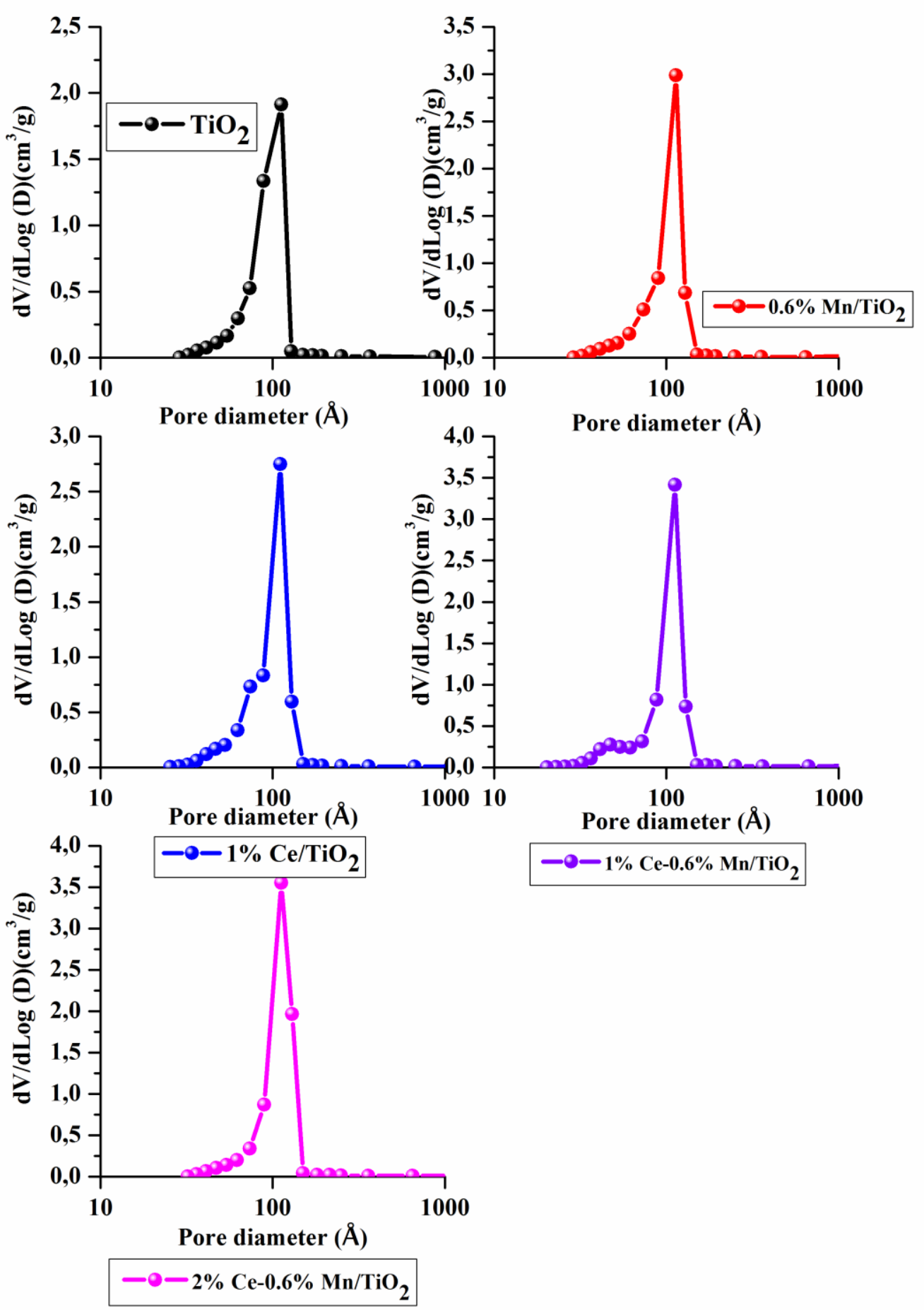

Fig (5): (a) $\mathrm{N}_{2}$ adsorption-desorption isotherms and (b) the $\mathrm{BJH}$ pore size distributions of the different samples. 

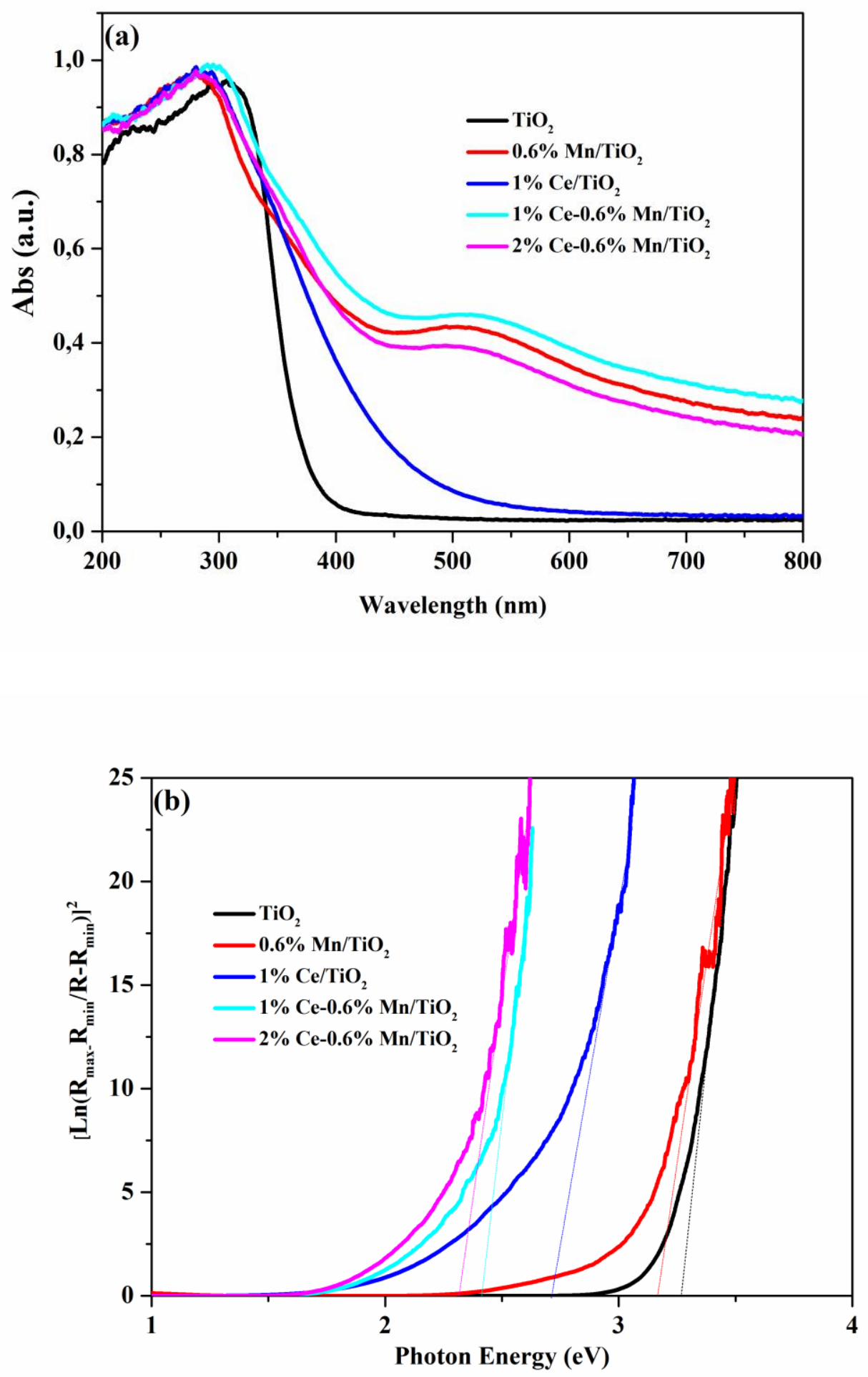

Fig (6): (a) UV-visible diffuse absorption spectra and (b) energies band gap of the different samples. 


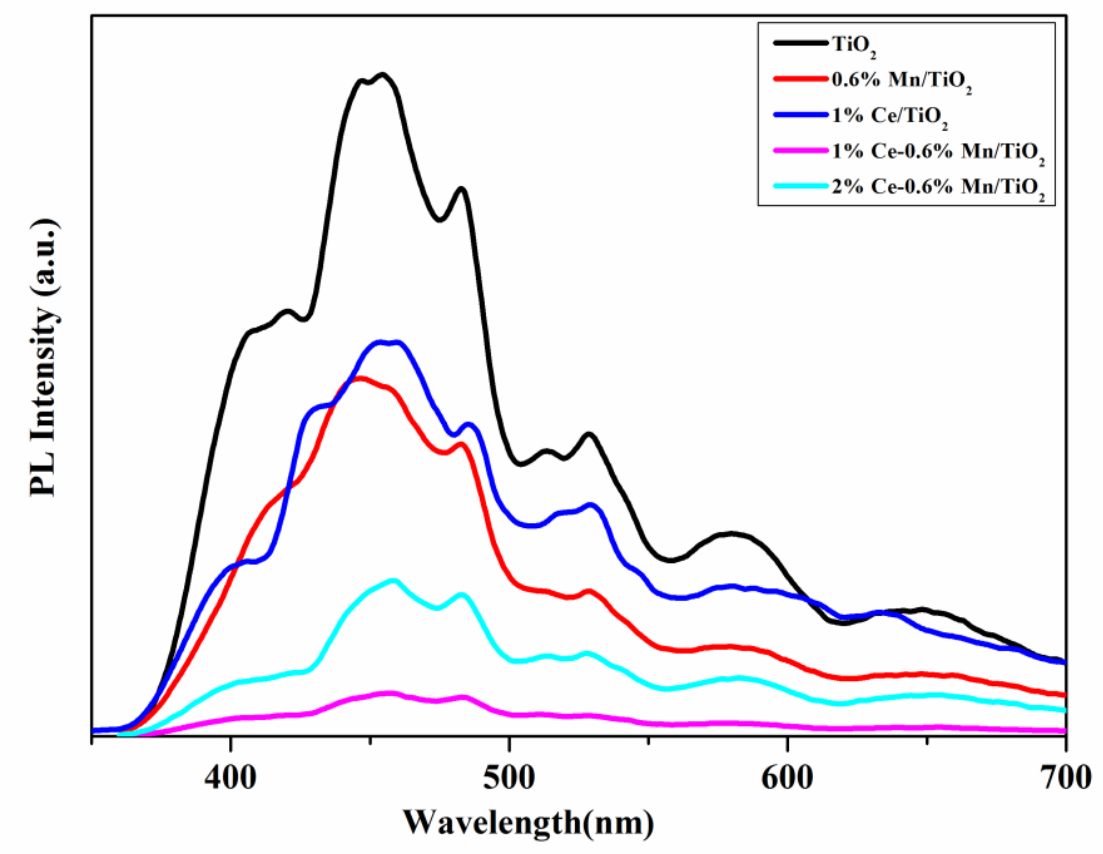

Fig (7): Photoluminescence spectra of the samples.

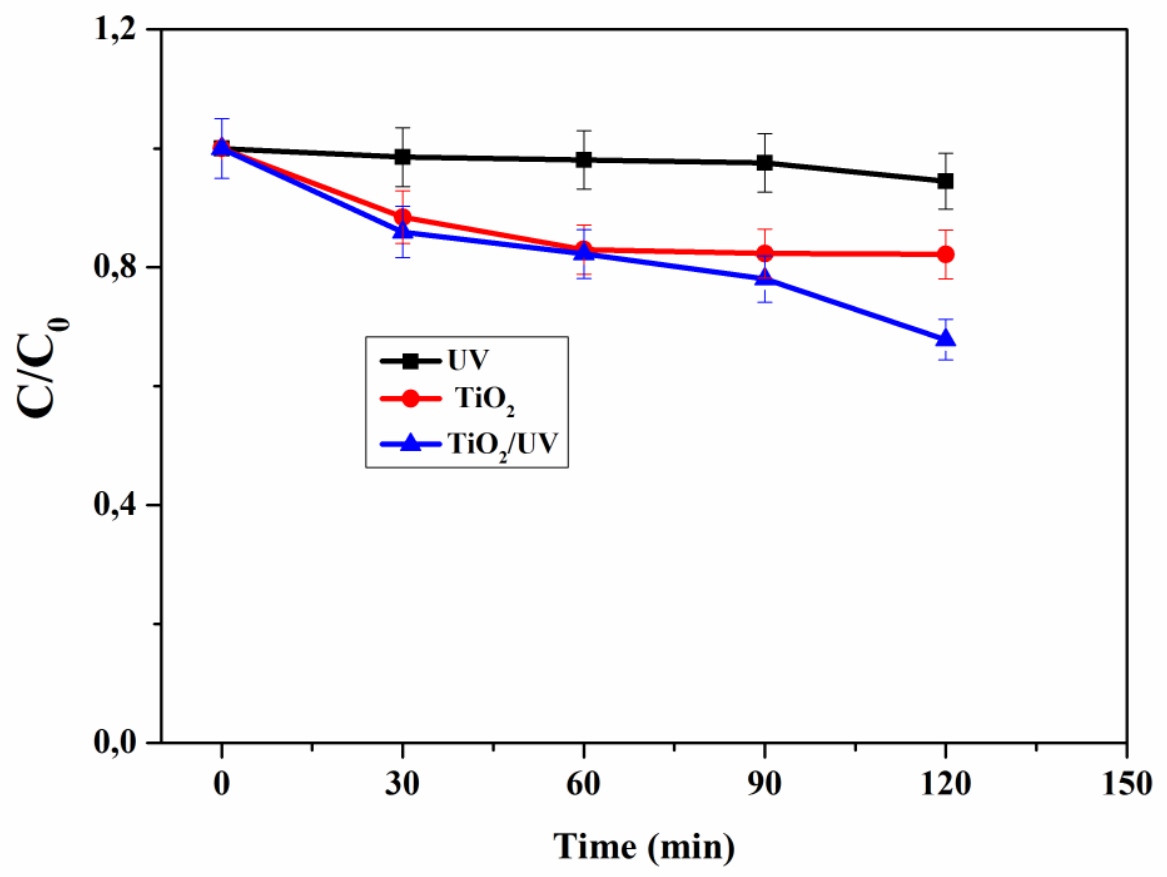

Fig (8): Effect of the adsorption, photolysis and the photocatalysis on the photodegradation of DCF, $[D C F]=10 \mathrm{mg} \mathrm{L}^{-1}, \mathrm{~m}_{\text {Cat }}=50 \mathrm{mg} \mathrm{L}^{-1}, \mathrm{pH}_{\mathrm{DCF}}=6, \lambda=254 \mathrm{~nm}$. 


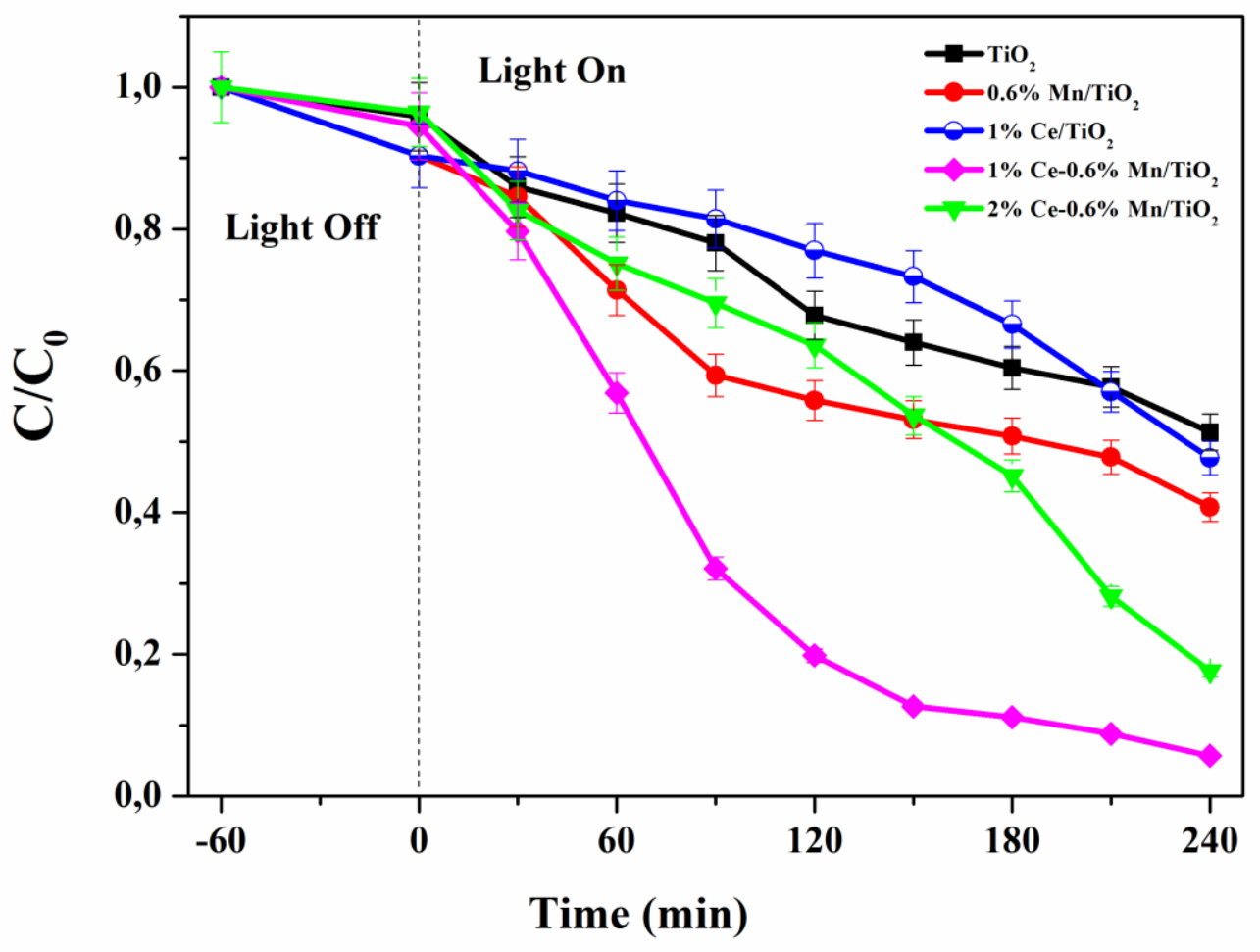

Fig (9): Photocatalytic performance of the materials on the DCF degradation sous UV $(254 \mathrm{~nm})$ irradiation, $[\mathrm{DCF}]=10 \mathrm{mg} \mathrm{L}^{-1}, \mathrm{~m}_{\mathrm{Cat}}=50 \mathrm{mg} \mathrm{L}^{-1}, \mathrm{pH}_{\mathrm{DCF}} \approx 6, \lambda=254 \mathrm{~nm}$.

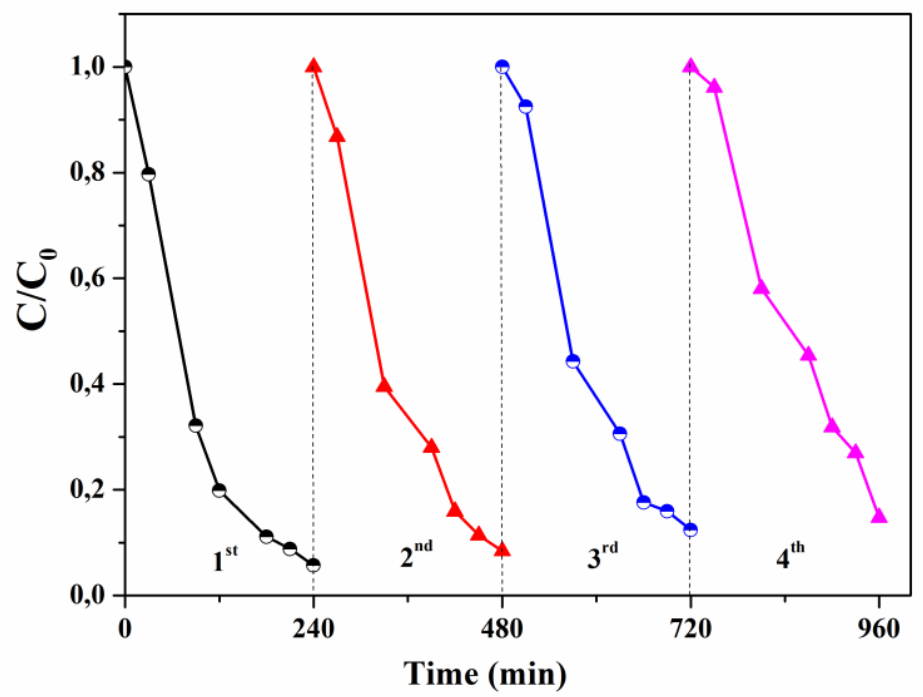

Fig (10): Cycling runs for photocatalytic degradation of diclofenac over $1 \% \mathrm{Ce}-0.6 \% \mathrm{Mn} / \mathrm{TiO}_{2}$ catalyst, $[\mathrm{DCF}]=10 \mathrm{mg} \mathrm{L}^{-1}, \mathrm{~m}_{\mathrm{Cat}}=50 \mathrm{mg} \mathrm{L}^{-1}, \mathrm{pH}$ DCF $\approx 6, \lambda=254 \mathrm{~nm}$. 


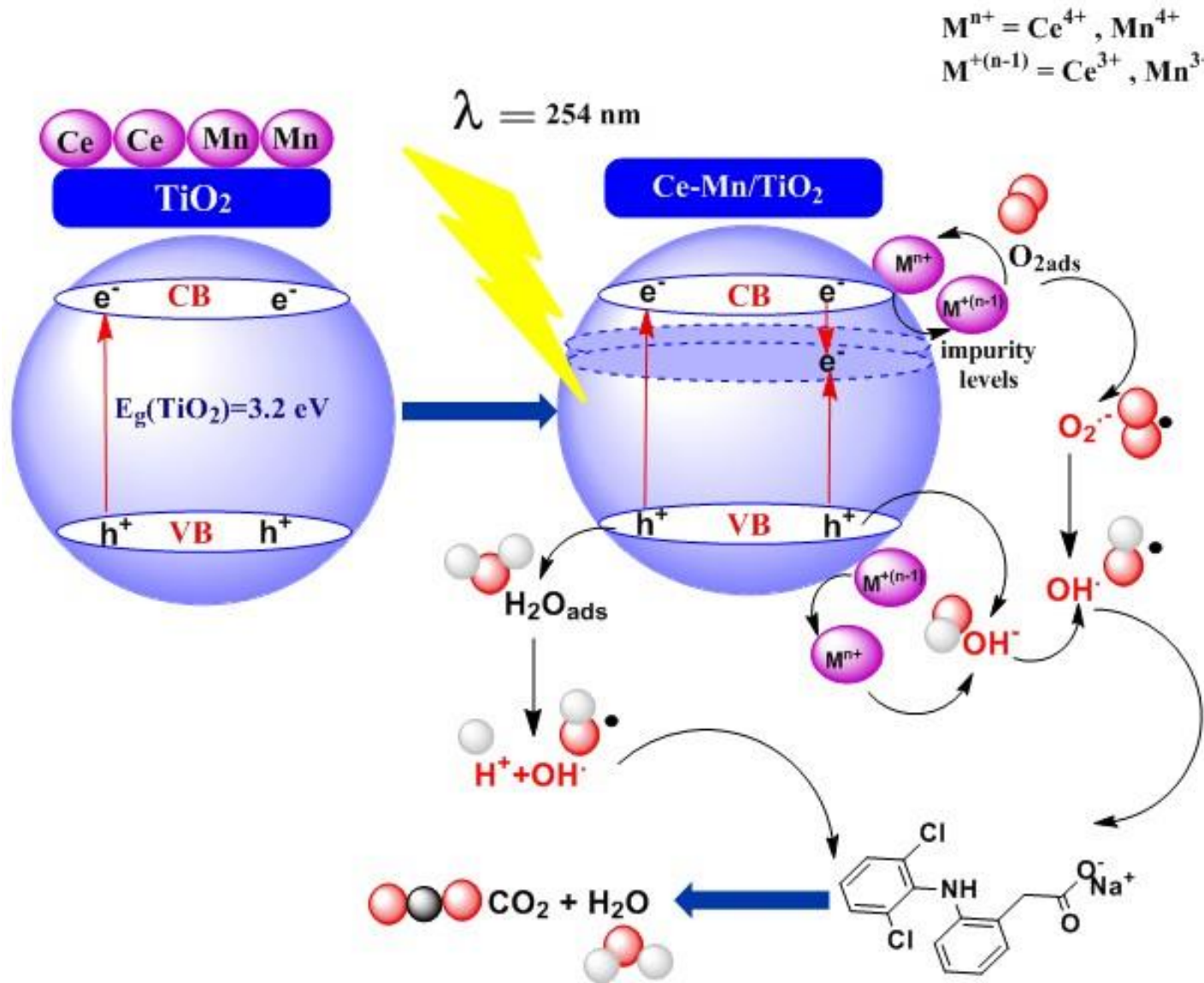

Scheme (1): Proposed photocatalytic mechanism of $\mathrm{Mn}-\mathrm{Ce} / \mathrm{TiO}_{2}$ catalyst under UV light irradiation. 